\begin{tabular}{|c|}
\hline PRE-PRINT (or SUBMITTED) version \\
\hline $\begin{array}{c}\text { Official published paper: } \\
\text { https://onlinelibrary.wiley.com/doi/full/10.1002/bse.2373 }\end{array}$ \\
\hline Free online accessible version (with restriction): \\
https://rdcu.be/bOUDP
\end{tabular}

\title{
Greenwashing and Environmental Communication: Effects on Stakeholders' Perceptions
}

\author{
Riccardo Torelli \\ University of Parma - Department of Economics and Management \\ Via J.F. Kennedy, 6 - 43125 Parma (Italy) \\ riccardo.torelli@unipr.it \\ Federica Balluchi \\ University of Parma - Department of Economics and Management \\ Arianna Lazzini \\ University of Modena and Reggio Emilia - Department of Communication and Economics
}

\begin{abstract}
Since the first Earth Day in the 1970s, corporate environmental performance has increased dramatically, and cases of greenwashing have increased sharply. The term greenwash refers to a variety of different misleading communications that aim to form overly positive beliefs among stakeholders about a company's environmental practices. The growing number of corporate social responsibility (CSR) claims, whether founded or not, creates difficulties for stakeholders in distinguishing between truly positive business performance and companies that only appear to embrace a model of sustainable development. In this context, through the lens of legitimacy and reporting theory, we intend to understand and assess the different impacts that various types of misleading communications about environmental issues have on stakeholders' perceptions of corporate environmental responsibility and greenwashing. Stakeholder responses to an environmental scandal will also be assessed. The hypotheses tested through a four-for-two design experiment reveal that different levels of greenwashing have a significantly different impact on stakeholders' perceptions of corporate environmental responsibility and stakeholders' reactions to environmental scandals.
\end{abstract}

Keywords: greenwashing; environmental communication; signaling theory; legitimacy theory; experiment; corporate social responsibility. 


\section{Introduction}

Since the mid-1960s, with the affirmation of the environmental movement, the phenomenon of misleading environmental communication has begun to be identified both at the level of actions and business strategies. This phenomenon was initially defined as "eco-pornography" by former advertising executive Jerry Mander. The term greenwashing was first coined in 1986 by biologist and environmental activist Jay Westerveld (Pearson, 2010), but it is from the seminal work of Greer and Bruno (1996) that the number of studies on greenwashing has grown significantly (Laufer, 2003), with a substantial leap in 2011 (Lyon and Montgomery, 2015). In the last decade, greenwashing has become an increasingly significant topic in the academic literature because of its growing operational importance and because it raises challenging issues and multidisciplinary research opportunities (Lyon and Montgomery, 2015).

Despite growing interest from academics and professionals, there is no generally accepted definition of greenwashing in the current literature. Due to its interdisciplinary nature, different definitions and perspectives have been adopted by scholars in the analysis of greenwashing practices (Guo et al., 2014; Nyilasy et al., 2014; Roulet and Touboul, 2015; Seele and Gatti, 2017; Wilson et al., 2010). In describing greenwashing, several scholars base themselves on the definition of the Oxford English Dictionary, others adopt the TerraChoice perspective, and others elaborate their own definition (Delmas and Burbano, 2011; Lyon and Montgomery, 2015; Walker and Wan, 2012). While the Oxford Dictionary defines greenwashing as "disinformation disseminated by an organisation so as to present an environmentally responsible public image", TerraChoice (2009) considers greenwashing "the act of misleading consumers regarding the environmental practices of a company or the environmental benefits of a product or service". Interesting perspectives are offered by Delmas and Burbano (2011), which considers greenwashing a "poor environmental performance and positive communication about environmental performance", and Lyon and Montgomery (2015), which finds that "the word greenwash is used to cover any communication that misleads people into adopting overly positive beliefs about an organization's environmental performance, practices, or products".

In recognising greenwashing as a misleading communication practice concerning environmental issues, many studies have tried to understand why and how firms engage in greenwashing (Du, 2015; Chen and Chang, 2013; Laufer, 2003; Testa et al., 2018a; Vries et al., 2015). According to Walker and Wan, there are two main motives for firms to engage in greenwashing: to obtain legitimacy (Cormier and Magnan, 2015) according to institutional (Oliver, 1991) and legitimacy theory (Suchman, 1995) and to communicate the firms' values with regard to green issues through a signal to stakeholders by engaging in symbolic actions or "green talk" (Connelly et al., 2011) according to signalling theory.

Although there is today a great deal of academic interest in greenwashing, the extant literature highlights the need for further research pointed to fulfilling some conceptual and empirical gaps 
(Lyon and Montgomery, 2015) and to studying the impacts and consequences both for stakeholders and firms' reputations of a corporate crisis due to a greenwashing scandal (Siano et al., 2017). Lyon and Montgomery (2015) highlight the need for further research aimed at a broader inquiry of the taxonomy of the greenwashing phenomenon. The authors suggest paying attention to the role of visual imagery and rhetorical language in shaping green communication and messaging. An interesting issue concerning greenwashing, although it is little considered in the extant literature, is whether and how it can affect the actions and reactions of stakeholders and consequently corporate reputation.

Our investigation, blending elements of legitimacy and signalling theory (Campbell, 2003), aims to flesh out a broader taxonomy of greenwashing related to distinct levels and typologies of communication. We aim to analyse, for different levels of communication, the impacts on stakeholder perception of corporate environmental responsibility and corporate greenwashing by measuring stakeholder reactions to environmental scandals. In our study, we adopt a fourby-two between-subjects design experiment, manipulating different levels of greenwashing and industry type (Cho et al., 2009).

The paper is organised into four main sections. The first section presents the theoretical background and the hypotheses. The second describes the research methods in terms of the participants, variables and experimental task. The third section presents and discusses the results, and the final section presents some conclusions.

\section{Background and hypotheses}

Previous studies have examined greenwashing at two main levels: at the company level and at the product level. At the corporate level, greenwashing is associated with a distorted dissemination of environmental issues that affect the entire company. At the product level, greenwashing is associated with an explicit strategy through which companies advertise, in an untruthful and distorted way, the environmental characteristics of a specific product or service (Delmas and Burbano, 2011; TerraChoice, 2009). If analysed at the company level, greenwashing is associated with distorted and/or selective disclosures in which companies disclose only good environmental strategies and actions, concealing negative ones. With this attitude, companies seek to generate a positive but totally misleading impression of the company's environmental performance (Lyon and Maxwell, 2011). Today, greenwashing at the company level is particularly significant both for the growing demand from stakeholders for high levels of responsibility and transparency (Bromley and Powell, 2012; Tang and Demeritt, 2018) and for the growing spread of real environmental crimes related to the so-called ecomafia or eco-criminality (Massari and Monzini, 2004; Rege and Lavorgna, 2017). In recent decades, due to the growing sensitivity of stakeholders to environmental issues, it seems that greenwashing has become a widespread attitude among companies to try to outdo their competitors (Parguel et al., 2011). Today, as a result, there is a growing scepticism on the part 
of stakeholders towards companies that communicate their environmental strategies (Prothero, et al., 1997) and performances (Chen and Chang, 2013). At the company level, greenwashing is a specific strategy that companies adopt to engage in symbolic communication about environmental issues without addressing them substantially in actions (Walker and Wan, 2012; Wong et al., 2014). While symbolic actions are associated with a company's future plans, substantive actions refer to what a company is currently doing. Greenwashing has its internal roots in the need to legitimise the company and lies in the essential perception that a company's actions are desirable, correct or appropriate within a socially constructed system of norms, values and beliefs (Suchman, 1995). According to previous studies (Dowling and Pfeffer, 1975; Lindblom, 1994), firms seeking to gain or maintain legitimacy have a greater incentive to use communication strategies to potentially influence stakeholders' perceptions. According to Umit et al. (2011), positive and negative information on corporate social and environmental responsibility influences the purchase, employment, and investment intentions of various stakeholders. Consequently, legitimacy became a critical feature for companies because it can lead to stronger trade relationships, better job applicants, greater access to resources and financial performance improvement (Aldrich and Fiol, 1994; Babiak and Trendafilova, 2011; DiMaggio and Powell, 1983; Deephouse, 1999; Oliver, 1991; Prakash, 2002; Walker and Wan, 2012).

In recent studies (Cho et al., 2009; Vries et al., 2015; Yoon et al., 2006), the importance of the antecedents of greenwashing has been analysed, focusing on how and why information provided by firms about the reasons for their activities in environmental measures can affect stakeholders' perceptions of corporate greenwashing. Vries et al. (2015) find that stakeholders often regard company communications about environmental issues as more rhetorical than real. People may be suspicious of the truthfulness of companies' environmental claims and may speculate about the subtle purposes (Forehand and Grier, 2003; Vries et al., 2015; Yoon et al., 2006). These findings highlight the need for companies to be cautious in disclosing their environmental strategies and activities. Corporate environmental initiatives are certainly appreciated by stakeholders, although they can be highly self-defeating if they should arouse suspicions of corporate greenwashing. Furthermore, it has been shown that, under certain circumstances, positive environmental disclosures have successfully offset the negative effects of liability exposures in people's minds (Cho et al., 2009; Milne and Patten, 2002). This phenomenon frequently occurs when companies engage in purely symbolic actions to signal to stakeholders their values and refer to the environment and green issues in a misleading way, choosing to engage in 'green talk' without a 'green walk' (Brunton et al., 2017; Ramus and Montiel, 2005). Such firms take advantage of the natural information asymmetry between the signaller and the receiver. Signalling theory is useful in analysing how parties that have access to different information interpret signals (Connelly et al., 2011) and to study the distortive effect of greenwashing (Seele and Gatti, 2017). 
Starting from the assumption that the intention of companies is to create effective and efficient signals for the different targets of reference, we argue that different types of communication (for example, different strategies behind the labels, sustainability reports, institutional communications and strategic behaviours) resulting from different approaches and strategic decisions produce different levels of greenwashing.

Each kind of greenwashing, which is intended as an intentionally misleading environmental communication, produces different reactions and responses from stakeholders (Collison et al., 2003). Some approaches can receive non-significant responses, but others can lead to reputation problems, scandals, protests, boycotts etc. Previous literature (see the top of the paragraph) about misleading environmental communication and greenwashing has studied the phenomenon and informed us about findings that take into consideration only two areas of greenwashing (the corporate level and product level). Through the careful study of the literature on the issue, and by taking into consideration the reading keys that legitimacy theory and signalling theory give us, we aim to introduce two new misleading environmental communication levels to try to better classify the types of communications related to greenwashing. We suggest that there could be four main levels of greenwashing, which are characterised by specific goals and communication procedures: the corporate level, strategic level, dark level and product level.

Corporate-level greenwashing concerns misleading environmental communication about data and aspects related to the actual firm's image and reputation. This level embodies a static dimension (i.e., the company name and logo, vision, standard adherence, and corporate certification.

Strategic level greenwashing concerns a misleading environmental communication concerning aspects related to the future firm's strategies (i.e., strategic public communication, corporate medium-long-term goals, strategic plan for improvement or implementation of technology/processes, report communication, and targeted extraordinary operations).

Dark level greenwashing concerns a misleading environmental communication finalised to hidden illegal activities (i.e., money laundering, criminal and/or mafia collusion, corruption, and investments with hidden aims).

Product level greenwashing concerns a misleading environmental communication concerning some specific features of a product or a family of products (i.e., label, targeted advertising, packaging, and product certifications).

The four levels of greenwashing are strictly connected to each other by a set of business processes and in the real context in which companies operate and stakeholders receive their communications, but we are interested in and have focused on the final step of the environmental communication process when the corporate signal arrives at the stakeholders with precise and distinct characteristics. Based on this set of distinctive signal characteristics, we have distinguished the four greenwashing levels explained above. 
To establish whether the levels exist in the real world and in the everyday experience of stakeholders and whether there are significant differences among them, we test the different impacts of these distinct levels on stakeholder perceptions of corporate environmental responsibility and corporate greenwashing and measure different stakeholder reactions to an environmental scandal at each level. We want to understand if the experiment will show significant differences in the perceptions and reactions of stakeholders depending on the level of greenwashing to which the participants will be assigned: the presence of significant differences would give us a first but valid element confirming the proposed existence of the distinct levels of communication.

According to the theoretical framework, we have developed four hypotheses to be tested.

H1 A misleading communication belonging to different levels of greenwashing will have a significantly different impact on stakeholder perceptions of corporate environmental responsibility.

Previous research highlights the role of disclosure content (Patten and Crampton, 2003) and the presentation of that content (Cho et al., 2009) in gaining legitimation and improving stakeholder perceptions of a company's social and environmental responsibility. Belonging to a typology of greenwashing and having certain communicational characteristics is closely related to disclosure content and presentation. We expect that the four main levels of greenwashing will have different impacts on the perceptions of environmental responsibility.

H2 A misleading communication belonging to different levels of greenwashing will have a significantly different impact on stakeholder perceptions of corporate greenwashing.

The characteristics of communication about investments and commitments towards environmental protection and environmental sustainability have an important and significant impact on the perceptions of corporate greenwashing (Vries et al., 2015). The motives behind investments and commitments, as well as the type of activity and corporate core business, are closely related to the perceptions of greenwashing (Vries et al., 2015). Further, belonging to different levels of greenwashing may have an impact on it.

H3 A misleading communication belonging to different levels of greenwashing will have a significantly different impact on stakeholder reactions to an environmental scandal.

Currently, the level of attention towards corporate environmental impacts and commitments is very high, and environmental scandals are a topical issue (Siano et al., 2017). Many studies have focused on the effects of stakeholder discovery of greenwashing; some have highlighted 
the effects on financial performance (Du, 2015; Testa et al., 2018b; Walker and Wan, 2012), while others have examined the impact on trust (Dekhili and Achabou, 2013; Perrini et al., 2010) and loyalty (Guo et al., 2017). We expect that the type of communication and the level of greenwashing will significantly affect stakeholder reactions to an environmental scandal relating to a greenwashing discovery.

$\mathrm{H}_{4} \quad$ The environmental sensitivity of the industry will amplify the impact of different levels of greenwashing.

It is widely known that the industry is an extremely important aspect in investigating nonfinancial disclosures, precise environmental disclosures and corporate and social responsibility (CSR) practices. Especially in the case of firms operating in environmentally sensitive industries (ESIs), it is necessary to identify the impact of the industry on stakeholder perceptions (Cho et al., 2006; Patten, 2002). ESI firms with poor environmental performance may engage in misleading environmental communication to gain legitimacy, counter suspicions of negative environmental impact and improve corporate perception and trust (Cho et al., 2009). In this research, we hypothesise that belonging to an ESI may widen the impact of each level of greenwashing on stakeholder perceptions of CSR and greenwashing, amplifying reactions to an environmental scandal.

The four hypotheses and the relationship among the constructs are summarised and shown below (Figure 1).

Figure 1. Experimental model

\section{[INSERT HERE]}

\section{Methodology}

To verify the different types of misleading communications, the impact on stakeholders, the reactions of stakeholders and the resulting effects on corporate legitimacy and reputation, we conducted an experiment using a four-by-two between-subjects design. To reach our aim, we have developed an experiment based on fictitious companies with defined characteristics. We have also developed a series of situations, giving the participants all the background information and details necessary to understand and judge the different types of misleading communications.

This section details the participants, the experimental task, the experimental procedures, and the operationalisation of the variables.

\section{Participants}


Similar to previous studies in this field of research (Cho et al., 2009; Nyilasy et al., 2014; Vries et al., 2015), the participants for this research work were undergraduate university students from the same country, and in line with the number of students involved in these previous studies (with attention to the number of students assigned to each experimental task level), we have engaged a sample of 201 students.

The choice to test our hypotheses on students is in line with previous experiment-based studies in this field. Our choice is based on the main assumption that students, as young people, are generally aware of and interested in environmental issues and are theoretically well informed, especially via the web, about recent events, scandals and official investigations. Furthermore, as frequent and expert users of the web, students are particularly affected by true and false environmental communications.

All the participants enrolled were undergraduate students in accounting classes from two different universities in the same country. None of these students had any basic or advanced knowledge (acquired during their university studies) about the CSR field of study and/or greenwashing issue. The students took part voluntarily in the experiment and received no credits, gifts or payments. The students were informed that the experiment would take approximately 15 minutes to complete, that participation was purely voluntary, and that all the information collected would be kept anonymous and the analyses would only be on an aggregate level. The request to make a good faith effort to complete the questionnaire was set as a condition for participation.

In the first phase, 54 students took part in a pilot test, and at the end, we made minor changes to the wording of some of the items of the questionnaire. In the main phase, a total of 147 participants completed the experiment, but 19 were eliminated because they failed the manipulation check. These students did not perceive the correct level of analysis of greenwashing (corporate, strategic, dark, product) or whether the classification of the industry was environmentally sensitive (ESI) or not environmentally sensitive (non-ESI). The final sample thus consisted of 128 usable surveys.

The gender distribution of the participants was balanced. Most participants were female (53\%) and 24 years old or younger (77\%), and their geographical origin was predominantly from north of the country (Table 1). The participants' attitudes towards social and environmental performance were specifically evaluated in the survey using a seven-point Likert scale. The average score expressed on this statement was 4.9.

Table 1. Descriptive data for the 128 participants providing usable responses

\section{[INSERT HERE]}


The experimental task aims to evaluate reactions to specific situations and any subsequent changes in the perception of reputation and corporate legitimacy. This task has been carried out by using both visual imagery and firms' verbal rhetoric. Previous studies (McQuarrie and Mick, 2003) suggested that visual imagery is more attention grabbing, elicits richer inferences and is more pleasurable and convincing than verbal statements. Nevertheless, little attention has been paid by scholars to the role of visual imagery and rhetoric in shaping green communications and messaging (Lyon and Montgomery, 2015). To prevent a distortion of the results due to preexisting corporate or brand perceptions (Aggarwal, 2004; Wagner et al., 2009), we used fictitious companies but realistic typologies of communication to test our hypotheses. To conceal the real aim of the experiment, the participants were told that the purpose of the study was an experiment about effective marketing communication strategies about social issues. The participants were divided into eight different classes, each of which concerned a different experimental set. Each participant viewed and completed only one set. Starting from the four different levels of greenwashing proposed in the previous section (corporate, strategic, dark, product) and the two industry typologies (ESI or non-ESI), we have identified and tested eight conditions:

1. Corporate level (ESI);

2. Corporate level (non-ESI);

3. Strategic level (ESI);

4. Strategic level (non-ESI);

5. Dark level (ESI);

6. Dark level (non-ESI);

7. Product level (ESI);

8. Product level (non-ESI).

To contemporaneously measure perceptions of corporate environmental responsibility (Variable 1) and corporate greenwashing (Variable 2), the experiment focused on the four levels of greenwashing and ESI/non-ESI companies (therefore, companies that do or do not belong to sectors with a high environmental impact, such as chemical, energy, waste and extraction).

The experiment took place in three steps. In the first step, we presented the company and its declared commitment to the environment. A PowerPoint presentation supplied visual information about the company and its commitment to the environment, and we also provided important information about the company for each experimental condition (see the Appendix for more details on the information given to the participants). Depending on the assigned level, the participants received and read information (in addition to an explanatory and meaningful image) on the company's environmental commitments, which were communicated to them using different methods, signals and procedures. For example, for the corporate level, an 
environmental communication was made through the company name and logo; for the strategic level, environmental objectives included in the long-term corporate strategy were used. For the dark level, corporate practices and contexts commonly recognised as connected to crime or the eco-mafia (construction, waste) were used; for the product level, we used advertising communications concerning a single product in common use.

In the first step, the specific sector in which the company operates was declared to the participants, and background information was provided. Each group was shown an image concerning, alternatively, the company logo, a specific label, a product or advertising campaign. Key and easily recognisable sectors (e.g., food and chemicals) have been used to characterise companies belonging to ESI or non-ESI experimental sets. At the end of the first step, the participants were asked to complete the first section of the questionnaire based on the images displayed and the information given. In the next phase, the participants were made aware of serious facts that led to the involvement of the same company in a serious environmental scandal. Finally, the participants were invited to complete the second section of the questionnaire. To measure the reactions to an environmental scandal (Variable 3), for each company presented, we provided information on its involvement in a scandal (e.g., the use of environmentally toxic paints and adhesives, release of harmful fumes in the air, use of illegal landfills; use of public funds related to the environment for the purchase of weapons and drugs). The scandals presented to the participants always regarded the violation or non-respect of an environmental commitment made and declared by the company (and presented in the information read in the first step) and, in addition, a further bad environmental practice, which was not directly related to the commitments made. In the last step, the participants completed the section on the manipulation check, demographic data and information on attitudes towards CSR performance (see the Appendix for further details about the questionnaire).

Similar to previous studies (Alewine, 2010; Cho et al., 2009; Falk and Heckman, 2009), we used a four-by-two between-subjects design experiment, manipulating the levels of greenwashing to understand the effects on stakeholders of the various levels of greenwashing implementation (the perception of corporate environmental responsibility and corporate greenwashing: dependent variables 1 and 2) and to analyse how the perceptions and actions of stakeholders change after a clear case of greenwashing (the reaction to an environmental scandal: dependent variable 3 ).

\section{Measurement of variables}

This study is based on three primary dependent variables: perceptions of corporate environmental responsibility, perceptions of corporate greenwashing and reactions to an environmental scandal. The items used to measure the variables are two items for the perceptions of corporate environmental responsibility, three items for the perceptions of 
corporate greenwashing and four items for the reactions to an environmental scandal. All the items were measured on a seven-point Likert-type scale with "completely false" and "completely true" as the anchors.

The first item used to measure perception of corporate environmental responsibility is based on Cho et al. (2009). We included a second item concerning environmental certification and standards to measure a further type of communication in the perception of corporate environmental responsibility. Previous studies (Berrone et al., 2017) demonstrated a close relationship between environmental legitimacy and environmental actions, such as environmental patents, environmental pay policies and environmental trademarks.

In accordance with Vries et al. (2015), we measured the perception of corporate greenwashing using three items via a seven-point Likert-type scale. These items evaluate the perceptions of the firm's hidden interests and its desire to appear more environmentally friendly to gain a more positive reputation and legitimacy.

To measure stakeholders' reactions to an environmental scandal, we considered four different aspects of their possible reaction to an environmental/green scandal: the loss of trust, the possibility of changing their opinion on the company scandal, the possibility of reassessing the company in the future if it proves to be behaving correctly, and, finally, the intention to boycott the company. For the variable reaction to scandals, since it has not yet been validated by the extant literature, we evaluated if the questions load properly onto this factor. The four items are shown as a valid scale with a Cronbach's alpha of 0.7684 .

Table 2 shows descriptive statistics for participants' mean responses for each of the nine items. The first two items (perception of corporate environmental responsibility) differed at a statistically significant level between greenwashing level conditions $(p<0.01$ and $\mathrm{p}<0.05)$. A difference at a statistically significant level $(p<0.01)$ also occurs in the fifth item (perceptions of corporate greenwashing), and two of the three items of this construct have a statistically significant difference between the ESI/non-ESI conditions. All four items measuring reaction to an environmental scandal differed at a statistically significant level between greenwashing level conditions and/or ESI/non-ESI conditions. (The value of $p$ is shown below the table.)

Table 2. Dependent variable scale items

\section{[INSERT HERE]}

\section{Results and discussion}

\section{H1: Impact on stakeholder perceptions of corporate environmental responsibility}

Table 3 shows descriptive statistics for the impact on stakeholder perceptions of corporate 
environmental responsibility for the four levels of greenwashing in the ESI and non-ESI conditions. Univariate tests show statistically significant differences $(p<0.01)$ for the corporate greenwashing level and dark greenwashing level, regardless of being ESI/non-ESI. The results show that company-level greenwashing is characterised by the highest degree of perceptions of corporate environmental responsibility, while the level of darkness demonstrates the lowest.

Table 3. Descriptive statistics of 'Perception of corporate environmental responsibility' (Variable 1)

\section{[INSERT HERE]}

The analysis of variance (ANOVA), presented in Table 4, indicates that the level of greenwashing related to stakeholders' perceptions of corporate environmental responsibility is again statistically significant $(p<0.01)$. The differences in perceptions of corporate environmental responsibility between the levels are depicted in Graph 1, which states the mean values of this variable for each experimental condition.

Table 4. Results of the ANOVA on 'Perceptions of corporate environmental responsibility' (Variable 2)

\section{[INSERT HERE]}

Graph 1 Histogram of 'Perceptions of corporate environmental responsibility': mean values identified in experimental condition

Hypothesis $1(H I)$ is supported. Misleading company communications have a significantly different impact on stakeholder perceptions of corporate environmental responsibility depending on which level they belong to. Corporate-type communications bring a higher level of responsibility perception and thus more easily increase legitimacy and reputation. Communications in the context of industries and activities often linked to organised crime and the mafia struggle to reach a high level of perception of corporate environmental responsibility, and this has substantial effects on corporate legitimacy and reputation. In the experiment set, the mafia and criminal activities are hidden and not explicitly declared so that the participants do not know if the company is linked to organised crime. The signal sent out by the company acts in a different way on stakeholders depending on the level of greenwashing it belongs to. For each level, the signal has distinctive characteristics, and the analysis reveals that these are, in effect, received and considered by stakeholders. 


\section{H2: Impact on stakeholder perceptions of corporate greenwashing}

Table 5 shows descriptive statistics for the second dependent variable by experimental conditions (greenwashing levels, ESI and non-ESI). The variable's mean value shows statistically significant differences $(p<0.05)$ for dark greenwashing levels regardless of whether they are ESI or non-ESI. This level is characterised by a higher perception of corporate greenwashing.

Table 5. Descriptive statistics of the 'Perceptions of corporate greenwashing' variable

\section{[INSERT HERE]}

The ANOVA presented in Table 6 shows the importance and significance of the ESI/non-ESI condition $(p<0.05)$ related to stakeholder perceptions of corporate greenwashing. The differences between the levels highlighted by the statistical analysis are clearly shown in Graph 2 but only for non-ESI conditions (see below for a discussion). The non-ESI mean values for product and dark levels are the anchors, with the lowest and the highest levels, respectively.

Table 6. Results of the ANOVA on the 'Perceptions of corporate greenwashing' variable

\section{[INSERT HERE]}

Graph 2 Histogram of 'Perceptions of corporate greenwashing': mean values identified in experimental condition

\section{[INSERT HERE]}

These results support Hypothesis 2 (H2). Depending on the level of greenwashing, a company's misleading environmental communications have significantly different impacts on stakeholders' perceptions of greenwashing. This result is particularly strong if the company operates in a context of criminal and mafia activities. Corporate- and strategic-level communications do not create a concrete perception of a misleading communication (greenwashing) in the stakeholders' minds. In line with the results for Hypothesis 1, these two levels result in an increase in reputation and trust compared to the perception of greenwashing. The perception of corporate greenwashing is higher when the signal is sent by a company 
operating in an industrial context and activities usually related to organised crime and the mafia. This result can feed into the mind of the stakeholder suspicions and preconceptions about the company being assessed. In addition, in this case, the signal acts in a different way on stakeholders depending on which greenwashing level it belongs to. This result can feed suspicions and preconceptions among stakeholders about the firm they are assessing. Furthermore, the signal acts differently on stakeholders depending on which of the different levels of greenwashing is considered. This result is particularly true for the dark level.

\section{H3: Impact on stakeholder reactions to an environmental scandal}

Table 7 reports descriptive statistics of the third dependent variable by experimental condition (greenwashing levels, ESI or non-ESI). The analysis performed on the variable's mean values shows statistically significant differences $(p<0.01)$ for corporate greenwashing levels and dark greenwashing levels regardless of being whether the firm is in an ESI or non-ESI (similar to the first variable in Table 3). The corporate-level results are characterised by a lower level of stakeholders' reactions to environmental scandal, while the dark level is characterised by a higher level.

Table 7. Descriptive statistics of the 'Reactions to an environmental scandal' variable

\section{[INSERT HERE]}

Table 8 presents the ANOVA in which the level of greenwashing is statistically significantly $(p<0.01)$ related to stakeholder reactions to an environmental scandal related to greenwashing. In Graph 3, the differences between the reactions of the different levels are clear. The mean values for the corporate level are related to a low level of reaction to a greenwashing scandal. However, the dark level shows a very high level of stakeholder reactions.

Table 8. Results of the ANOVA on the 'Reactions to an environmental scandal' variable

\section{[INSERT HERE]}

Graph 3 Histogram of 'Reactions to an environmental scandal': mean values identified in experimental condition 
Hypothesis $3(H 3)$ is also supported. For each condition tested, the experimental set showed the participants a serious environmental scandal. The characteristics of the firm's signals, the legitimacy obtained, and the suspicion of greenwashing all led to different intensities of stakeholder reactions. There are significantly different impacts on stakeholders' reactions to an environmental scandal involving greenwashing depending on which level the signal belongs to. Depending on the level of reputation and legitimacy obtained with the level of misleading communication and possible suspicions of greenwashing, the corporate level is related to a low level of reaction to scandal. Signals belonging to the dark level lead to a high level of stakeholder reactions, which may be related to the severity of the consequences of the misleading communications (and the related hidden activity) as well as a moral and legal point of view. In the case of scandal, we explicated and stated the presence of the mafia and organised crime in the experiment set.

\section{H4: Role of ESIs in amplifying impacts of different levels of greenwashing}

Regarding the role of the environmental sensitivity of an industry and its moderator or amplifier effect on the impacts of different levels of greenwashing, Table 5 (Perceptions of corporate greenwashing) and Table 7 (Reactions to an environmental scandal) show statistically significant differences $(\mathrm{p}<0.05$ and $p<0.1)$ for the ESI and non-ESI conditions. The ESI experimental conditions are characterised by higher stakeholder perceptions of corporate greenwashing and reactions to an environmental scandal. Moreover, participants who evaluated the situation of an ESI company reported a stronger reaction. Regarding the ANOVA analyses, the findings highlight that the ESI condition is statistically significantly $(\mathrm{p}<0.05$ and $p<0.1)$ related to perceptions of corporate greenwashing (Table 6) and to stakeholder reactions to an environmental scandal involving greenwashing (Table 8). In the ANOVA findings related to perceptions of corporate environmental responsibility, there is also a statistically significant $(p<0.1)$ effect on the interaction between belonging to an ESI and greenwashing level conditions. Graph 3 also clearly shows the role of belonging to an ESI on the impact of different levels of misleading communication. The environmental sensitivity of the industry amplifies the impact of different greenwashing levels on stakeholder reactions to an environmental scandal, which is interesting and certainly deepens the mirror role of the ESI/non-ESI condition for product level and dark level, respectively, as shown in Graph 2 regarding perceptions of corporate greenwashing. The histograms show a clear and strong amplifier role of belonging to an ESI for environmental communications and signal belonging to the product area of greenwashing but also an amplifier role of belonging to a non-ESI for communications related to the dark area of greenwashing.

Our research findings indicate that stakeholders, when faced with environmental communications related to a single product (i.e., labels, advertising and packaging), are 
sensitive and receptive about which type of industry the company belongs to, especially when the company belongs to a high environmental impact industry. In contrast, when stakeholders are faced with the environmental communications of a company belonging to an industry typically related to organised crime, the moderator/amplifier role of the ESI/non-ESI condition is confused and not directly clear and determinable. This result suggests that, when stakeholders are faced with signals belonging to the "dark area of greenwashing" in an ESI condition, their attention is mostly oriented on environmental aspects rather than on the criminal aspects of the communication and the company. In contrast, in the other condition (non-ESI), stakeholders' attention falls entirely on the crime aspect. Hypothesis 4 (H4) is significantly confirmed. When a scandal occurs and the greenwashing practice is discovered, stakeholders' reactions are stronger if the firm operates in an environmentally sensitive industry. This result suggests that stakeholders are most affected by environmental damage when there is greater potential danger. Public awareness and desire for environmental protection are therefore higher in ESIs.

\section{Conclusions}

The purpose of this study was to examine the effects on stakeholders of the different levels of greenwashing, understanding if and how stakeholders' perceptions and actions change after an assessed case of greenwashing.

Our research findings, based on previous studies highlighting the characteristics of communication (Vries et al., 2015) and the role of information disclosure (Patten and Crampton, 2003) and presentation (Cho et al., 2009) in gaining legitimation and improving stakeholder perceptions, indicate that different levels of greenwashing have significantly different impacts on stakeholders' perceptions of corporate environmental responsibility and stakeholders' reactions to environmental scandals. The findings also highlight that belonging to an ESI amplifies the impact of different greenwashing levels on stakeholders' perceptions of and reactions to environmental scandals. Firms reach different goals by implementing specific communication strategies related to specific organisational and decision-making processes. Industry environmental sensitivity must be carefully considered in all communicational aspects because of its key role in amplifying the impact of greenwashing levels on stakeholders' reactions.

Similar to all empirical studies, our investigation is subject to certain limitations. The first limitation concerns the internal and external validity of our research design. Although the design has high internal validity, with two dependent variables being measured by previously tested confirmed items, the experimental design also includes four new items that measure reactions to an environmental scandal construct. To address the problem of external validity, we used fictitious companies but a realistic typology of communication for each greenwashing level, as well as realistic visual imagery and environmental scandals based on real world events. The second limitation concerns the typology of the experiment participants who are exclusively 
undergraduate students. However, as young people, these students are aware of and interested in environmental issues and are usually well informed (especially via the Internet) about recent events, scandals and official investigations. Additionally, being frequent users of the web, these students are particularly affected by (true or false) environmental communications.

Limitations aside, the results of our analysis may be useful for companies in planning and implementing communication processes to avoid suspicion and loss of legitimacy. These results may also help firms understand the consequences that symbolic communication strategies can have on stakeholders and on corporate legitimacy overall. Stakeholders may also find the results of help in understanding greenwashing and the actions and strategies it uses. NGOs will find insight for further investigations and actions and to better address their attention, resources and time. Both stakeholders and NGOs will gain a better understanding of the different types of greenwashing and be better able to take account of the main effects of environmental communications on the development of perceptions and suspicions. Finally, the study will enrich the academic study of greenwashing, misleading corporate communications and environmental responsibility, and it fills a gap in the literature about the distinction between and subdivision of greenwashing practices at different levels and relating to different effects. Future research is encouraged to refine the different levels of classification of greenwashing, enriching the classifications proposed with other possible levels of misleading environmental communication. Research would also be useful to test the levels theorised in other countries, using other categories of stakeholders and a sample more varied in age and educational level. It would also be interesting to investigate the possible role of NGOs in identifying types of greenwashing and moderating or amplifying its impact on stakeholders.

\section{References}

Aggarwal, P. (2004). The effects of brand relationship norms on consumer attitudes and behavior. Journal of Consumer Research, 31: 87-101.

Aldrich, H.E., and Fiol, C.M. (1994). Fools rush in? The institutional context of industry creation. Academy of Management Review, 19: 645-670.

Alewine, H.C. (2010). A model for conducting experimental environmental accounting research. Sustainability Accounting, Management and Policy Journal, 1(2): 256-291.

Alniacik, U., Alniacik, E., and Genc, N. (2011). How corporate social responsibility information influences stakeholders' intentions. Corporate Social Responsibility and Environmental Management 18: 234-245.

Babiak, K., and Trendafilova, S. (2011). CSR and environmental responsibility: Motives and pressures to adopt green management practices. Corporate Social Responsibility and Environmental Management 18: 11-24. 
Berrone, P., Fosfuri, A., and Gelabert, L. (2017). Does greenwashing pay off? Understanding the Relationship Between Environmental Actions and Environmental Legitimacy. Journal of Business Ethics, 144(2), 363-379.

Bromley, P., and Powell, W.W. (2012). From smoke and mirrors to walking the talk: decoupling in the contemporary world. The Academy of Management Annals, 6(1), 483530.

Brunton, M., Eweje, G., and Taskin, N. (2017). Communicating Corporate Social Responsibility to Internal Stakeholders: Walking the Walk or Just Talking the Talk? Business Strategy and the Environment, 26(1), 31-48.

Campbell, D. (2003). Intra- and intersectoral effects in environmental disclosures: evidence for legitimacy theory? Business Strategy and the Environment, 12(6), 357-371.

Chen, Y.S., and Chang, C.H. (2013). Greenwash and green trust: The mediation effects of green consumer confusion and green perceived risk. Journal of Business Ethics, 114, 489500

Cho, C.H., Patten, D.M. and Roberts, R.W. (2006). Corporate political strategy: An examination of the relation between political expenditures, environmental performance, and environmental disclosure. Journal of Business Ethics, 67(2), 139-54.

Cho, C. H., Phillips, J. R., Hageman, A. M., and Patten, D. M. (2009). Media richness, user trust, and perceptions of corporate social responsibility: An experimental investigation of visual web site disclosures. Accounting, Auditing and Accountability Journal, 22(6), 933-952.

Collison, D., Lorraine, N., and Power, D. (2003). An exploration of corporate attitudes to the significance of environmental information for stakeholders. Corporate Social Responsibility and Environmental Management 10(4): 199-211.

Connelly, B. L., Certo, S. T., Ireland, R. D., and Reutzel, C. R. (2011). Signaling Theory: A Review and Assessment. Journal of Management, 37(1), 39-67.

Cormier, D., and Magnan, M. (2015). The Economic Relevance of Environmental Disclosure and its Impact on Corporate Legitimacy: An Empirical Investigation. Business Strategy and the Environment, 24(6), 431-450.

Delmas, M. A., and Burbano, V. C. (2011). The Drivers of Greenwashing. California Management Review, 54(1), 64-87.

Deephouse, D.L. (1999). To be different, or to be the same? It's a question (and theory) of strategic balance. Strategic Management Journal, 20, 147-166.

Dekhili, S., and Achabou, M. A. (2013). Price Fairness in the Case of Green Products: Enterprises' Policies and Consumers' Perceptions. Business Strategy and the Environment, 22(8), 547-560. 
DiMaggio, P., and Powell, W.W. (1983). The iron cage revisited: Collective rationality and institutional isomorphism in organizational fields. American sociological review, 48(2), $147-160$.

Dowling, J., and Pfeffer, J. (1975). Organizational legitimacy: social values and organizational behavior. Pacific Sociological Review, 18, 122-136.

$\mathrm{Du}$, X. (2015). How the Market Values Greenwashing? Evidence from China. Journal of Business Ethics, 128(3), 547-574.

Falk, A., and Heckman, J.J. (2009). Lab Experiments are a major source of knowledge in the social sciences. Science, 326(5952), 535-538.

Forehand, M.R., and Grier, S. (2003). When is honesty the best policy? The effect of stated company intent on consumer skepticism. Journal of Consumer Psychology, 13, 349356.

Greer, J., and Bruno, K. (1996). Greenwash: The reality behind corporate environmentalism. Reality behind corporate environmentalism. New York: Apex Press.

Guo, R., Tao, L., Li, C., and Wang, T. (2017). A Path Analysis of Greenwashing in a Trust Crisis Among Chinese Energy Companies: The Role of Brand Legitimacy and Brand Loyalty. Journal of Business Ethics, 140(3), 523-536.

Laufer, W. S. (2003). Social Accountability and Corporate Greenwashing. Journal of Business Ethics, 43(3), 253-261.

Lindblom, C.K. (1994). The implications of organizational legitimacy for corporate social performance and disclosure. In Critical Perspectives on Accounting Conference, New York.

Lyon, T.P., and Maxwell, J.W. (2011). Greenwash: Corporate environmental disclosure under threat of audit. Journal of Economics and Management Strategy, 20(1), 3-41.

Lyon, T. P., and Montgomery, A. W. (2015). The Means and End of Greenwash. Organization and Environment, 28(2), 223-249.

Mahoney, L.S., Thorne, L., Cecil, L. and LaGore, W. (2013). A research note on standalone corporate social responsibility reports: signalling or greenwashing? Critical Perspectives on Accounting, 24(4/5), 350-359.

Massari, M., and Monzini, P. (2004). Dirty businesses in Italy: A case-study of illegal trafficking in hazardous waste. Global Crime, 6(3-4): 285-304.

McQuarrie, E.F., and Mick, D.G. (2003). The contribution of semiotic and rhetorical perspectives to the explanation of visual persuasion in advertising. In L.G. Scott and R. Batra (Eds.), Persuasive imagery: A consumer response perspective (pp. 191-221). Mahwah, NJ: Erlbaum.

Meyer, J.W., and Rowan, B. (1977). Institutionalized organizations: Formal structure as myth and ceremony. American journal of sociology, 83(2), 340-363. 
Mitchell, R. K., Agle, B. R., and Wood, D. J. (1997). Toward a Theory of Stakeholder Identification and Salience: Defining the Principle of Who and What Really Counts. Academy of Management Review, 22(4), 853-886.

Milne, M.J., and Patten, D.M. (2002). Securing organizational legitimacy: An experimental decision case examining the impact of environmental disclosures. Accounting, Auditing and Accountability Journal, 15(3), 372-405.

Neu, D., Warsame, H. and Pedwell, K. (1998), Managing public impressions: environmental disclosures in annual reports, Accounting, Organizations and Society, 23(3), 265-282.

Nyilasy, G., Gangadharbatla, H., and Paladino, A. (2014). Perceived Greenwashing: The Interactive Effects of Green Advertising and Corporate Environmental Performance on Consumer Reactions. Journal of Business Ethics, 125(4), 693-707.

Oliver, C. (1991). Strategic responses to institutional processes. Academy of Management Review, 16(1), 145-179.

Parguel, B., Benoît-Moreau, F., and Larceneux, F. (2011). How sustainability ratings might deter 'greenwashing': A closer look at ethical corporate communication. Journal of business ethics, 102(1): 15-28.

Patten, D.M. (2002). The relation between environmental performance and environmental disclosure: A research note. Accounting, Organizations and Society, 27(8), 763-73.

Patten, D.M., and Crampton, W. (2003). Legitimacy and the internet: An examination of corporate web page environmental disclosures. Advances in Environmental Accounting and Management, 2, 31-57.

Pearson J. (2010). Are we doing the right thing. Journal of Corporate Citizenship, 37, 37-40.

Perrini, F., Castaldo, S., Misani, N., and Tencati, A. (2010). The impact of corporate social responsibility associations on trust in organic products marketed by mainstream retailers: a study of Italian consumers. Business Strategy and the Environment, 19(8), $512-526$.

Prakash, A. (2002). Green marketing, public policy and managerial strategies. Business Strategy and the Environment, 11(5), 285-297.

Prothero, A., Peattie, K., and McDonagh, P. (1997). Communicating greener strategies: a study of on-pack communication. Business Strategy and the Environment, 6(2), 74-82.

Ramus, C. A., and Montiel, I. (2005). When Are Corporate Environmental Policies a Form of Greenwashing? Business and Society, 44(4), 377-414.

Rege, A., and Lavorgna, A. (2017). Organization, operations, and success of environmental organized crime in Italy and India: A comparative analysis. European Journal of Criminology, 14(2), 160-182.

Roulet, T., and Touboul, S. (2015). The Intentions with Which the Road is Paved: Attitudes to Liberalism as Determinants of Greenwashing. Journal of Business Ethics, 128(2), 305320. 
Salancik, G.R., and Pfeffer, J. (1978). A social information processing approach to job attitudes and task design. Administrative science quarterly, 224-253.

Seele, P., and Gatti, L. (2017). Greenwashing Revisited: In Search of a Typology and Accusation-Based Definition Incorporating Legitimacy Strategies. Business Strategy and the Environment, 26(2), 239-252.

Siano, A., Vollero, A., Conte, F., and Amabile, S. (2017). "More than words": Expanding the taxonomy of greenwashing after the Volkswagen scandal. Journal of Business Research, 71, 27-37.

Suchman, M. C. (1995). Managing Legitimacy: Strategic and Institutional Approaches. Academy of Management Review, 20(3), 571-610.

Tang, S., and Demeritt, D. (2018). Climate Change and Mandatory Carbon Reporting: Impacts on Business Process and Performance. Business Strategy and the Environment, 27(4), 437-455.

TerraChoice (2009). The seven sins of greenwashing. Available at http://sinsofgreenwashing.com/findings/greenwashing-report-2009/index.html. (accessed 28/03/2018).

Testa, F., Boiral, O., and Iraldo, F. (2018a). Internalization of environmental practices and institutional complexity: can stakeholders pressures encourage greenwashing? Journal of Business Ethics, 147(2), 287-307.

Testa, F., Miroshnychenko, I., Barontini, R., and Frey, M. (2018b). Does it pay to be a greenwasher or a brownwasher? Business Strategy and the Environment, 27(7), 11041116.

Vries, G., Terwel, B. W., Ellemers, N., and Daamen, D. D. L. (2015). Sustainability or Profitability? How Communicated Motives for Environmental Policy Affect Public Perceptions of Corporate Greenwashing. Corporate Social Responsibility and Environmental Management, 22(3), 142-154.

Wagner, T., Lutz, R.J. and Weitz B.A. (2009). Corporate hypocrisy: Overcoming the threat of inconsistent corporate social responsibility perceptions. Journal of Marketing, 73, 7791.

Walker, K., and Wan, F. (2012). The Harm of Symbolic Actions and Green-Washing: Corporate Actions and Communications on Environmental Performance and Their Financial Implications. Journal of Business Ethics, 109(2), 227-242.

Wilson, A., Robinson, S., and Darke, P. (2010). When Does Greenwashing Work? Consumer Perceptions of Corporate Parent and Corporate Societal Marketing Firm Affiliation. Advances in Consumer Research, 37, 931-932.

Wong, C. W. Y., Lai, K.-H., Shang, K.-C., and Lu, C.-S. (2014). Uncovering the Value of Green Advertising for Environmental Management Practices. Business Strategy and the Environment, 23(2), 117-130. 
Yoon, Y., Gürhan-Canli, Z., and Schwarz, N. (2006). The effect of corporate social responsibility (CSR) activities on companies with bad reputations. Journal of Consumer Psychology, 16, 377-390. 


\section{Tables}

Table 1. Descriptive data for the 128 participants providing usable responses

\begin{tabular}{lc}
\hline & Sample $(\%)$ \\
\hline Age & 77 \\
24 or younger & 14 \\
$25-29$ & 9 \\
30 or older & \\
Gender & 47 \\
Male & 53 \\
Female & \\
Geographic origin & 78 \\
North & 6 \\
Centre & 16 \\
South & \\
\hline
\end{tabular}

Table 2. Dependent variable scale items

\begin{tabular}{|c|c|c|c|c|}
\hline & Mean & SD & Min & Max \\
\hline \multicolumn{5}{|l|}{ Dependent variable 1: Perceptions of corporate environmental responsibility } \\
\hline $\begin{array}{l}\text { Q1: I perceive a concrete attention and responsibility towards environmental } \\
\text { issues }\end{array}$ & 5.38 & $(1.06)^{\mathrm{b}}$ & 1 & 7 \\
\hline Q2: Certification or adherence to a standard confirms or increases my trust & 5.86 & $(0.99)^{\mathrm{a}}$ & 2 & 7 \\
\hline \multicolumn{5}{|l|}{ Dependent variable 2: Perceptions of corporate greenwashing } \\
\hline $\begin{array}{l}\text { Q3: The company presents itself as environmentally aware in order to improve its } \\
\text { reputation }\end{array}$ & 6.05 & $(0.83)$ & 3 & 7 \\
\hline Q4: The company has hidden intentions and interests & 4.28 & $(1.14)^{\mathrm{c}}$ & 1 & 7 \\
\hline Q5: The company presents itself as more environmentally aware than it actually is & 4.62 & $(1.21)^{\mathrm{a} ; \mathrm{c}}$ & 1 & 7 \\
\hline \multicolumn{5}{|l|}{ Dependent variable 3: Reactions to an environmental scandal } \\
\hline Q6: I have lost trust in the company after the environmental scandal & 6.31 & $(0.91)^{\mathrm{d}}$ & 3 & 7 \\
\hline $\begin{array}{l}\text { Q7: Even if I had more information, I would not change my opinion on the } \\
\text { company }\end{array}$ & 4.87 & $(1.56)^{\mathrm{a}}$ & 1 & 7 \\
\hline Q8: I will no longer re-evaluate the company, even if its behaviour seems correct & 4.49 & $(1.53)^{\mathrm{a}}$ & 1 & 7 \\
\hline Q9: In the future, I will avoid the company & 5.10 & $(1.31)^{\mathrm{a} ; \mathrm{c}}$ & 1 & 7 \\
\hline
\end{tabular}

a: $p<0.01$ (Significantly different between levels)

${ }^{\mathrm{b}}: p<0.05$ (Significantly different between levels)

c: $p<0.05$ (Significantly different between industries)

$\mathrm{d}: p<0.1$ (Significantly different between industries)

Table 3. Descriptive statistics of 'Perceptions of corporate environmental responsibility' (Variable 1)

\begin{tabular}{lccccccccc}
\hline \multirow{2}{*}{ Level } & \multicolumn{3}{c}{ ESI } & \multicolumn{3}{c}{ non-ESI } & \multicolumn{3}{c}{ Row means $($ level $)$} \\
& $N$ & Mean & SD & $n$ & Mean & SD & $n$ & Mean & SD \\
\hline Product & 20 & 5.40 & $(1.02)$ & 20 & 5.60 & $(0.77)$ & 40 & 5.50 & $(0.90)$ \\
Corporate & 15 & 6.03 & $(0.48)$ & 13 & 6.04 & $(0.48)$ & 28 & 6.04 & $(0.47)^{* * *}$ \\
Strategic & 19 & 5.74 & $(0.82)$ & 13 & 5.73 & $(0.53)$ & 32 & 5.73 & $(0.71)$ \\
Dark & 16 & 5.63 & $(0.69)$ & 12 & 4.75 & $(1.36)$ & 28 & 5.25 & $(1.10)^{* * *}$ \\
Column means (industry) & 70 & 5.68 & $(0.82)$ & 58 & 5.55 & $(0.93)$ & 128 & 5.62 & $(0.87)$ \\
\hline
\end{tabular}


Table 4. Results of the ANOVA on 'Perceptions of corporate environmental responsibility' (Variable 2)

\begin{tabular}{lcccc}
\hline & Sum of squares & Mean square & $F$-statistic & Statistical significance \\
\hline Overall model & 15.32 & 2.19 & 3.28 & 0.0032 \\
Industry & 0.88 & 0.88 & 1.32 & 0.2529 \\
Level & 10.91 & 3.63 & 5.45 & 0.0015 \\
Industry * Level & 5.14 & 1.71 & 2.57 & 0.0576 \\
\hline
\end{tabular}

Table 5. Descriptive statistics of the 'Perceptions of corporate greenwashing' variable

\begin{tabular}{lccccccccc}
\hline \multirow{2}{*}{ Level } & \multicolumn{3}{c}{ ESI } & \multicolumn{3}{c}{ non-ESI } & \multicolumn{3}{c}{ Row means (level) } \\
& $n$ & Mean & SD & $n$ & Mean & SD & $n$ & Mean & SD \\
\hline Product & 20 & 5.30 & $(0.74)$ & 20 & 4.65 & $(0.90)$ & 40 & 4.97 & $(0.88)$ \\
Corporate & 15 & 4.98 & $(0.75)$ & 13 & 4.69 & $(0.63)$ & 28 & 4.85 & $(0.70)$ \\
Strategic & 19 & 4.96 & $(0.59)$ & 13 & 4.77 & $(0.79)$ & 32 & 4.88 & $(0.68)$ \\
Dark & 16 & 5.25 & $(0.66)$ & 12 & 5.25 & $(0.53)$ & 28 & 5.25 & $(0.60)^{* *}$ \\
Column means (industry) & 70 & 5.13 & $(0.69)^{* *}$ & 58 & 4.81 & $(0.77)$ & 128 & 4.98 & $(0.74)$ \\
\hline$* 0.05$ & & & & & & & & &
\end{tabular}

Table 6. Results of the ANOVA on the 'Perceptions of corporate greenwashing' variable

\begin{tabular}{lcccc}
\hline & Sum of squares & Mean square & $F$-statistic & Statistical significance \\
\hline Overall model & 7.92 & 1.13 & 2.19 & 0.0398 \\
Industry & 2.46 & 2.46 & 4.77 & 0.0309 \\
Level & 2.98 & 0.99 & 1.92 & 0.1299 \\
Industry * Level & 1.92 & 0.64 & 1.24 & 0.2995 \\
\hline
\end{tabular}

Table 7. Descriptive statistics of the 'Reactions to an environmental scandal' variable

\begin{tabular}{|c|c|c|c|c|c|c|c|c|c|}
\hline \multirow{2}{*}{ Level } & \multicolumn{3}{|c|}{ ESI } & \multicolumn{3}{|c|}{ non-ESI } & \multicolumn{3}{|c|}{ Row means (level) } \\
\hline & $n$ & Mean & SD & $n$ & Mean & $\mathrm{SD}$ & $n$ & Mean & SD \\
\hline Product & 20 & 5.20 & $(1.15)$ & 20 & 5.14 & $(0.93)$ & 40 & 5.17 & $(1.03)$ \\
\hline Corporate & 15 & 4.80 & $(1.09)$ & 13 & 4.59 & $(0.77)$ & 28 & 4.71 & $\begin{array}{l}(0.95)^{* *} \\
*\end{array}$ \\
\hline Strategic & 19 & 5.47 & $(0.82)$ & 13 & 4.69 & $(1.16)$ & 32 & 5.16 & $(1.03)$ \\
\hline Dark & 16 & 5.83 & $(0.97)$ & 12 & 5.69 & $(0.87)$ & 28 & 5.77 & $\begin{array}{c}(0.91)^{* *} \\
*\end{array}$ \\
\hline Column means (industry) & 70 & 5.33 & $(1.06)^{*}$ & 58 & 5.03 & $(1.00)$ & 128 & 5.19 & $(1.04)$ \\
\hline
\end{tabular}

**** $: p<0.01$

$*: p<0.1$

Table 8. Results of the ANOVA on the 'Reactions to an environmental scandal' variable

\begin{tabular}{lcccc}
\hline & Sum of squares & Mean square & $F$-statistic & Statistical significance \\
\hline Overall model & 21.15 & 3.02 & 3.12 & 0.0046 \\
Industry & 2.72 & 2.72 & 2.81 & 0.0963 \\
Level & 15.91 & 5.30 & 5.48 & 0.0015 \\
Industry * Level & 2.59 & 0.86 & 0.89 & 0.4485 \\
\hline
\end{tabular}




\section{Figure}

Figure 1. Experimental model

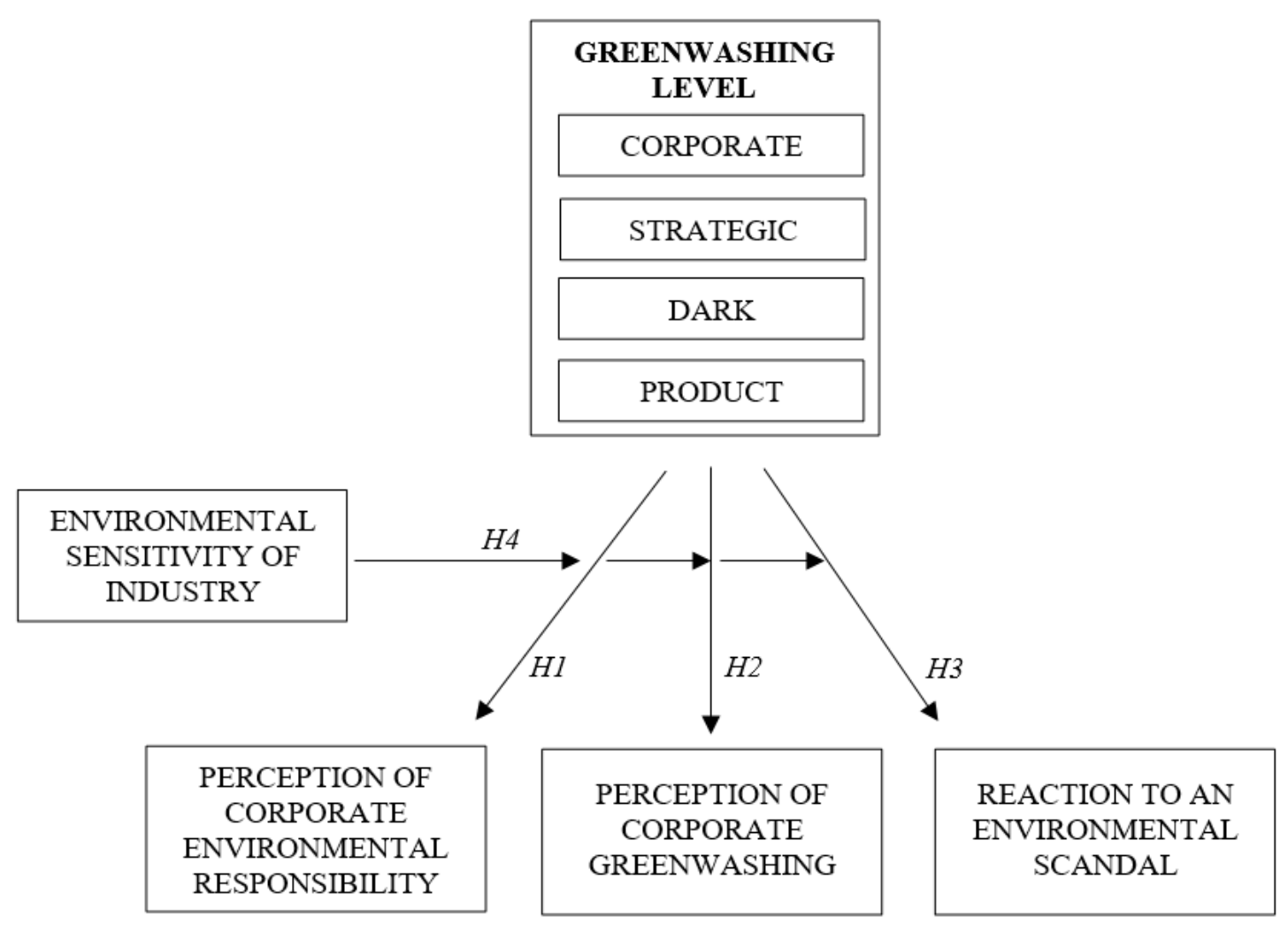

Figure 2. (Graph 1) Histogram of 'Perception of corporate environmental responsibility': mean values identified in experimental condition 


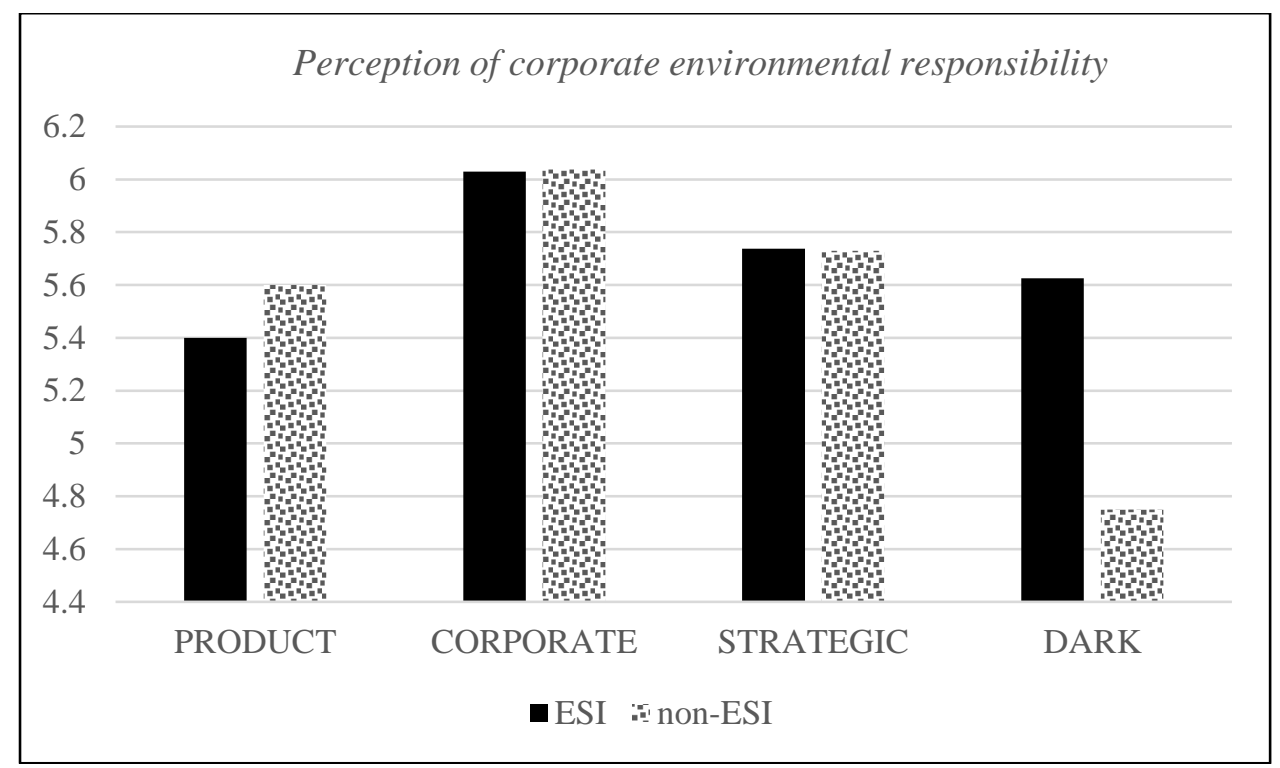

Figure 3. (Graph 2) Histogram of 'Perception of corporate greenwashing': mean values identified in experimental condition

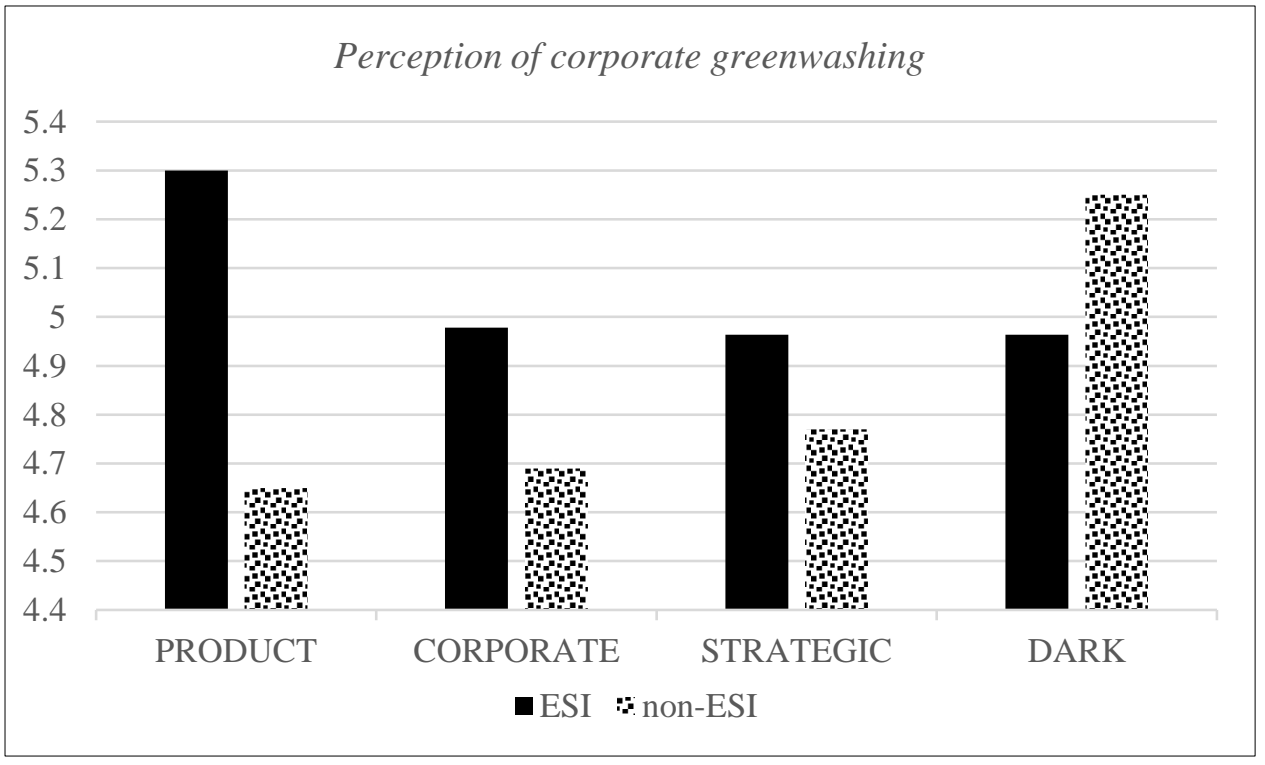

Figure 4. (Graph 3) Histogram of 'Reaction to an environmental scandal': mean values identified in experimental condition 


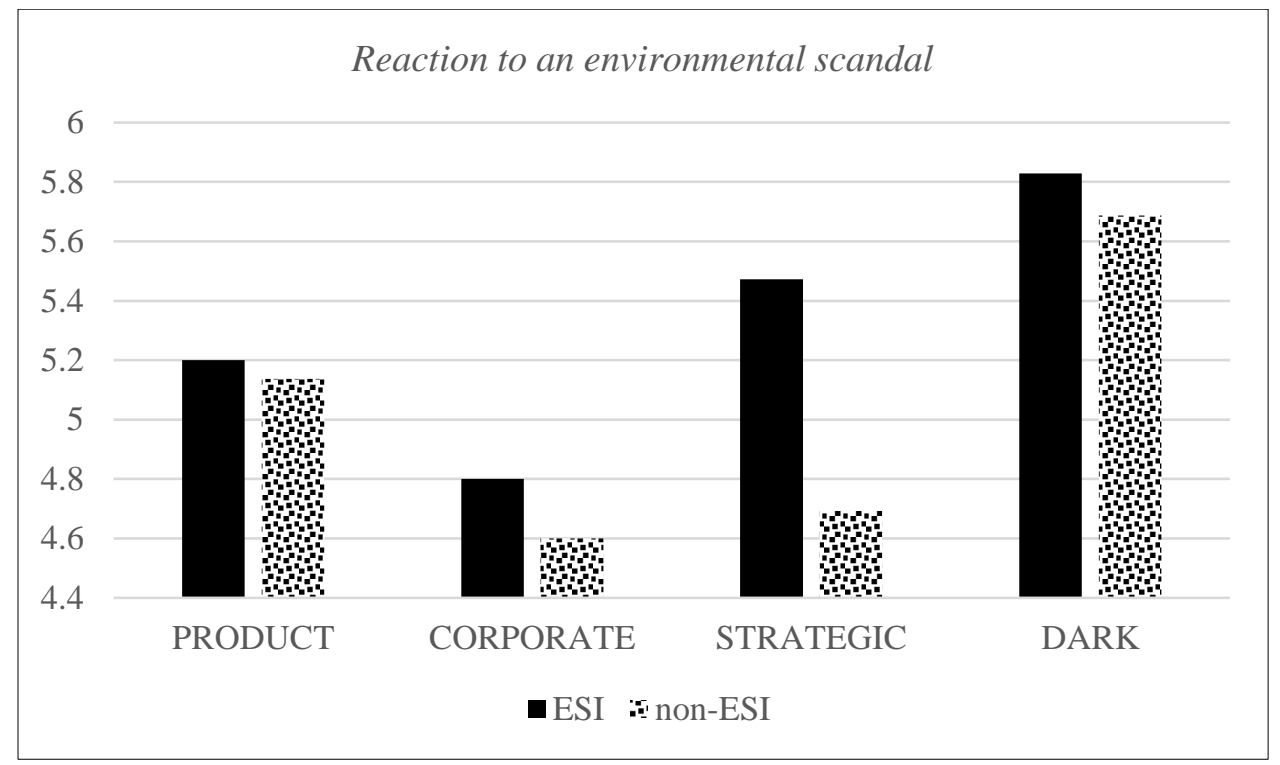

\section{Appendices}

$\underline{\text { See official published paper }}$ 